\title{
The J-Curve Phenomenon in Hypertension
}

\author{
Yuan-Yuan Kang Ji-Guang Wang
}

Centre for Epidemiological Studies and Clinical Trials, Shanghai Key Laboratory of Hypertension, The Shanghai Institute of Hypertension, Department of Hypertension, Ruijin Hospital, Shanghai Jiaotong University School of Medicine, Shanghai, China

\section{Key Words}

J-curve phenomenon · Hypertension · Blood pressure - Cardiovascular disease · Stroke .

Coronary artery disease $\cdot$ Antihypertensive treatment

\begin{abstract}
Almost immediately after antihypertensive therapy was proven effective in preventing cardiovascular events, the J-curve issue emerged as a hot topic. The Hypertension Optimal Treatment (HOT) trial attempted to address this question (diastolic blood pressure $<80,<85$, and $<90 \mathrm{~mm} \mathrm{Hg}$ ) but ended up with a post hoc analysis indicating a nadir of $138.5 \mathrm{~mm} \mathrm{Hg}$ systolic and $82.6 \mathrm{~mm} \mathrm{Hg}$ diastolic blood pressure. Nevertheless, this observational finding was supported by the results of observational studies in the general population and by post hoc analyses of antihypertensive treatment trials. The currently ongoing Systolic Hypertension Optimal Treatment (SHOT) trial investigates whether the relationship between systolic blood pressure and stroke recurrence is linear or J-shaped by treating systolic blood pressure to $<125,<135$, and $<145 \mathrm{~mm} \mathrm{Hg}$ in patients with a history of recent stroke. This trial may provide additional but probably inconclusive evidence, because optimal blood pressure might differ between individuals and across outcomes. Nevertheless, a universal beneficial, instead of optimal, level of blood pressure for antihypertensive treatment may exist approximating 130/80 $\mathrm{mm} \mathrm{Hg}$ and should be investigated by comparing 130/80 $\mathrm{mm} \mathrm{Hg}$ with 140/90 $\mathrm{mm} \mathrm{Hg}$ as a target blood pressure in hypertensive patients with the simultaneous use of modern blood pressure measuring techniques, such as home and ambulatory blood pressure monitoring.
\end{abstract}


Kang and Wang: The J-Curve Phenomenon in Hypertension

\section{Introduction}

Almost immediately after antihypertensive therapy was proven effective in preventing cardiovascular complications [1, 2], the J-curve discussion emerged to warn against the risks of a low or a too low blood pressure either as a physiologic or pathologic state or as a consequence of antihypertensive drug treatment $[3,4]$. In theory, there must be a turning point of blood pressure below which the risk of cardiovascular events increases, because blood pressure is essential for the blood perfusion of all organs, such as the brain, heart, and kidneys. In the research setting, there is strong evidence that the relationship between blood pressure and cardiovascular risk is direct and strong from 115/70 mm Hg of systolic/diastolic blood pressure upwards [5]. Nonetheless, studies repeatedly demonstrated a J-curve relationship between blood pressure and cardiovascular risk in various populations [6-14]. Clinical trialists attempted to address this question by randomized controlled trials [15]. Some believe that a three-group trial should be designed to prove or refute the J-curve hypothesis [16]. However, such a trial is difficult to conduct, because blood pressure separation between groups can be small and insufficient. Others designed trials to compare intensive to less intensive or to the so-called standard blood pressure lowering, with [17-20] or without goals of blood pressure control [21,22]. Such trials do not provide direct evidence concerning the question 'whether there is a J-curve', regardless of the results.

Until now, the J-curve issue apparently remains unresolved [16]. It is possible that the issue cannot be resolved, because the optimal blood pressure may vary between individuals, across organs, and with many conditions. Blood pressure changes over time, even within every single cardiac cycle from systole to diastole and over arteries from the central aorta to the peripheral arteries. Experts on blood pressure monitoring suggest that the wise thing to do is to measure blood pressure accurately and comprehensively by performing blood pressure monitoring in and outside the clinic and on various arterial sites. These suggestions point to future research on blood pressure-lowering treatment including the J-curve issue.

In this article, we review the literature on the J-curve phenomenon in hypertension, discuss the concept, mechanisms and evidence, and put forward current conclusions and future research.

\section{The Concept of the J-Curve Phenomenon}

Although Stewart [3] first reported higher risks of myocardial infarction in patients who achieved a diastolic blood pressure below $90 \mathrm{~mm} \mathrm{Hg}$ than in those with a blood pressure in the range of 100-109 mm Hg more than 30 years ago, it was Cruickshank [4] who described the J-curve phenomenon in the incidence of myocardial infarction and on-treatment diastolic blood pressure, with the lowest incidence at diastolic blood pressure levels of 85-90 $\mathrm{mm} \mathrm{Hg}$ (table 1). The J-curve phenomenon was first observed in connection with myocardial infarction for diastolic blood pressure in treated hypertension $[3,4]$ but was expanded to total and cardiovascular mortality [12], dementia [23], stroke [24, 25], etc., to systolic blood pressure [12, 25] and to other patient [7, 13, 24, 25] or general populations [23]. However, it is clinically relevant only with treated hypertension or the use of drugs with antihypertensive action in other clinical conditions. Low blood pressure because of frailty, failing left ventricle (systolic pressure), or stiffened arteries (diastolic pressure) may be detrimental but is not really relevant for cardiovascular prevention and, hence, should not be confused with the J-curve issue in the treatment of hypertension. 
Table 1. Characteristics of the studies that evaluated the J-curve phenomenon in hypertension

\begin{tabular}{|c|c|c|c|c|c|c|}
\hline $\begin{array}{l}\text { First author or } \\
\text { acronym [ref.] }\end{array}$ & $\begin{array}{l}\text { Year of } \\
\text { publi- } \\
\text { cation }\end{array}$ & $\begin{array}{l}\text { Total } \\
\text { number of } \\
\text { subjects }\end{array}$ & $\begin{array}{l}\text { Entry } \\
\text { criteria of } \\
\text { age, years }\end{array}$ & Patients & $\begin{array}{l}\text { Nadir SBP/DBP, } \\
\text { mm Hg }\end{array}$ & Comment \\
\hline \multicolumn{7}{|c|}{ Prospective observational studies } \\
\hline Stewart [3] & 1979 & 169 & Middle age & $\begin{array}{l}\text { Uncomplicated and } \\
\text { treated hypertension }\end{array}$ & $/ 100-109$ & $\begin{array}{l}\text { BP should seldom be } \\
\text { reduced by }>22 \%\end{array}$ \\
\hline Cruickshank [4] & 1987 & 932 & $17-77$ & $\begin{array}{l}\text { Moderate to severe } \\
\text { treated hypertension }\end{array}$ & $/ 85-90$ & $\begin{array}{l}\text { J-curve phenomenon in } \\
\text { ischemic heart disease }\end{array}$ \\
\hline \multicolumn{7}{|c|}{ Post hoc analysis of RCTs on antihypertensive treatment } \\
\hline INVEST $[8,41]$ & 2006 & 22,576 & $\geq 50$ & Hypertensive and CAD & $\begin{array}{l}119 / 84 \\
\text { (unadjusted); } \\
129 / 74 \\
\text { (adjusted) }\end{array}$ & $\begin{array}{l}\text { J-curve relationship with } \\
\text { DBP for all-cause mortality } \\
\text { and MI }\end{array}$ \\
\hline ONTARGET $[9,40]$ & 2009 & 25,588 & $>55$ & $\begin{array}{l}\text { CAD, PAD or CV disease } \\
\text { or DM plus organ } \\
\text { damage }\end{array}$ & $130 /$ & $\begin{array}{l}\text { In patients with baseline SBP } \\
<130 \mathrm{~mm} \mathrm{Hg} \text {, CV mortality } \\
\text { increased with further SBP } \\
\text { reduction }\end{array}$ \\
\hline VALUE [42] & 2015 & 15,245 & $\geq 55$ & $\begin{array}{l}\text { Hypertension and high } \\
\text { CV risk }\end{array}$ & $120 /$ & $\begin{array}{l}\text { Possible J-curve for BP } \\
\text { values close to the } \\
\text { recommended goals }\end{array}$ \\
\hline \multicolumn{7}{|c|}{ Post hoc analysis of RCTs on other cardiovascular treatment } \\
\hline OPTIMA [36] & 2009 & 477 & $>60$ & $\begin{array}{l}\text { Dementia, cognitive } \\
\text { impairment, and } \\
\text { controls }\end{array}$ & $/ 85$ & $\begin{array}{l}\text { The rate of cognitive decline } \\
\text { showed a U-shaped } \\
\text { dependence on DBP }\end{array}$ \\
\hline TNT [12] & 2010 & 10,001 & $35-75$ & $\begin{array}{l}\text { Clinically evident CAD } \\
\text { and LDL < } 130 \mathrm{mg} / \mathrm{dl}\end{array}$ & $146.3 / 81.4$ & $\begin{array}{l}\text { Exponential increase in the } \\
\text { risk of primary outcome for } \\
\mathrm{BP}<110-120 / 60-70 \mathrm{~mm} \mathrm{Hg}\end{array}$ \\
\hline PROVE IT [11] & 2010 & 4,162 & $\geq 18$ & $\begin{array}{l}\text { Acute coronary } \\
\text { syndrome patients }\end{array}$ & $136 / 85$ & $\begin{array}{l}\text { Too low BP goals (especially } \\
<110 / 70 \mathrm{~mm} \mathrm{Hg} \text { ) may be } \\
\text { dangerous }\end{array}$ \\
\hline VADT [13] & 2011 & 1,791 & Mean 60.4 & $\begin{array}{l}\text { Hypertension and type } \\
2 \text { DM }\end{array}$ & - & $\begin{array}{l}\text { Elevated risk when DBP }<70 \\
\mathrm{~mm} \mathrm{Hg}\end{array}$ \\
\hline \multicolumn{7}{|c|}{ RCTs that specifically investigated the J-curve phenomenon } \\
\hline HOT [15] & 1998 & 18,790 & $50-80$ & Hypertension & 138.8/82.6 & $\begin{array}{l}\text { Analysis not adjusted for } \\
\text { baseline confounders within } \\
\text { BP strata }\end{array}$ \\
\hline SHOT [16] & Ongoing & 7,500 & $65-79$ & $\begin{array}{l}\text { Hypertension and } \\
\text { stroke or TIA }\end{array}$ & - & - \\
\hline
\end{tabular}

$\mathrm{BP}=$ Blood pressure; $\mathrm{CAD}=$ coronary artery disease; $\mathrm{CV}=$ cardiovascular; $\mathrm{DBP}$ = diastolic blood pressure; $\mathrm{DM}=$ diabetes mellitus; $\mathrm{LDL}=$ low-density lipoprotein; $\mathrm{MI}=$ myocardial infarction; PAD = peripheral artery disease; RCTs = randomized controlled trials; $\mathrm{SBP}=$ systolic blood pressure; TIA = transient ischemic attack.

\section{Plausible Mechanisms of the J-Curve Phenomenon}

One general simple mechanism for the J-curve phenomenon in treated hypertension could be that the treated blood pressure is too low to perfuse a sufficient amount of blood into critical organs, such as the heart, brain, and kidneys. However, the threshold below which the blood perfusion decreases differs not only between individuals but also between organs within an individual. Several factors may have a significant influence on the J-curve phenomenon. 
Table 2. Characteristics of trials that compared intensive with less intensive blood pressure lowering

\begin{tabular}{|c|c|c|c|c|c|c|}
\hline $\begin{array}{l}\text { First author or } \\
\text { acronym [ref.] }\end{array}$ & $\begin{array}{l}\text { Year of } \\
\text { publi- } \\
\text { cation }\end{array}$ & $\begin{array}{l}\text { Total } \\
\text { number of } \\
\text { subjects }\end{array}$ & $\begin{array}{l}\text { Entry } \\
\text { criteria of } \\
\text { age, years }\end{array}$ & Patients & Treatment or goal BP & Comment \\
\hline \multicolumn{7}{|c|}{ Intensive vs. less intensive BP lowering without defined goals } \\
\hline ADVANCE [21] & 2007 & 11,140 & $\geq 55$ & $\begin{array}{l}\text { Hypertension and type } \\
2 \text { DM }\end{array}$ & $\begin{array}{l}\text { Perindopril/ } \\
\text { indapamide } \\
\text { combination vs. } \\
\text { placebo }\end{array}$ & No evidence of J-curve \\
\hline NAVIGATOR [29] & 2010 & 9,306 & $\geq 50$ & $\begin{array}{l}\text { CAD, CV risk factors or } \\
\text { impaired glucose } \\
\text { tolerance }\end{array}$ & Valsartan vs. placebo & $\begin{array}{l}\text { Valsartan led to a } 21 \% \\
\text { reduction in the incidence } \\
\text { of stroke but did not } \\
\text { reduce the rate of CV } \\
\text { events }\end{array}$ \\
\hline ROADMAP [22] & 2011 & 4,447 & $18-75$ & $\begin{array}{l}\text { Hypertension and type } \\
2 \text { DM }\end{array}$ & Olmesartan vs. placebo & $\begin{array}{l}\text { Among patients with } \\
\text { pre-existing CAD, those in } \\
\text { the lowest quartile of SBP } \\
\text { and those in the highest } \\
\text { quartile of SBP reduction } \\
\text { during the double-blind } \\
\text { treatment had the highest } \\
\text { rates of CV disease }\end{array}$ \\
\hline \multicolumn{7}{|c|}{ Intensive vs. less intensive BP lowering with defined goals } \\
\hline ACCORD-BP [19] & 2007 & 4,733 & $>55$ & $\begin{array}{l}\text { Hypertension and type } \\
2 \text { DM }\end{array}$ & $\begin{array}{l}\text { SBP }<120 \text { vs. }<140 \\
\mathrm{~mm} \mathrm{Hg}\end{array}$ & No significant difference \\
\hline JATOS [17] & 2008 & 4,418 & $65-85$ & Hypertensive patients & $\begin{array}{l}\text { SBP }<130 \text { vs. }<140 \\
\mathrm{~mm} \mathrm{Hg}\end{array}$ & No significant difference \\
\hline VALISH [18] & 2010 & 3,260 & $70-84$ & $\begin{array}{l}\text { Isolated systolic } \\
\text { hypertension }\end{array}$ & $\begin{array}{l}\mathrm{SBP} \geq 140 \text { to }<150 \text { vs. } \\
<140 \mathrm{~mm} \mathrm{Hg}\end{array}$ & No significant difference \\
\hline $\begin{array}{l}\text { INTERACT2 } \\
{[31,32]}\end{array}$ & 2013 & 2,839 & Mean 63.2 & $\begin{array}{l}\text { ICH and SBP } 150-220 \\
\mathrm{~mm} \mathrm{Hg}\end{array}$ & $\begin{array}{l}\text { Intensive }(<140 \\
\mathrm{mm} \mathrm{Hg}) \text { vs. less } \\
\text { intensive BP lowering }\end{array}$ & $\begin{array}{l}\text { Intensive BP lowering } \\
\text { better }\end{array}$ \\
\hline SPRINT [20] & 2015 & 9,361 & $>50$ & $\begin{array}{l}\text { Hypertension with an } \\
\text { increased CV risk and } \\
\text { without DM or a } \\
\text { history of stroke }\end{array}$ & $\begin{array}{l}\text { SBP }<120 \text { vs. }<140 \\
\mathrm{~mm} \mathrm{Hg}\end{array}$ & SBP $<120 \mathrm{~mm} \mathrm{Hg}$ better \\
\hline
\end{tabular}

$\mathrm{BP}=$ Blood pressure; $\mathrm{CAD}$ = coronary artery disease; $\mathrm{CV}$ = cardiovascular; $\mathrm{DM}$ = diabetes mellitus; $\mathrm{ICH}=$ intracerebral hemorrhage; SBP = systolic blood pressure.

First, atherosclerotic plaques may cause arterial stenosis and decrease blood perfusion in vessels distal to the plaques. If the blood pressure is too low, the perfusion pressure in the distal arteries would be even lower, which will cause ischemia in tissues. In chronic conditions, ischemia will cause structural and functional remodeling and dysfunction [26]. In acute conditions, for instance ischemia induced by abrupt blood pressure drop, ischemic events will occur in critical organs. In the Randomized Olmesartan and Diabetes Microalbuminuria Prevention (ROADMAP) trial, although blood pressure lowering with olmesartan $40 \mathrm{mg}$ daily significantly reduced the risk of microalbuminuria, it significantly increased the risk of cardiovascular mortality [22] (table 2). This increase in the risk of fatal events was mainly observed in patients with coronary heart disease and a lower blood pressure at baseline [22]. The number of cardiovascular deaths, fatal myocardial infarctions, and sudden deaths was small in both the olmesartan $(15,5$, and 7 , respectively) and the placebo groups $(3,0$, and 1 , respectively) [22]. Nonetheless, the observation strongly suggests the importance of arterial stenosis in the J-curve phenomenon. 


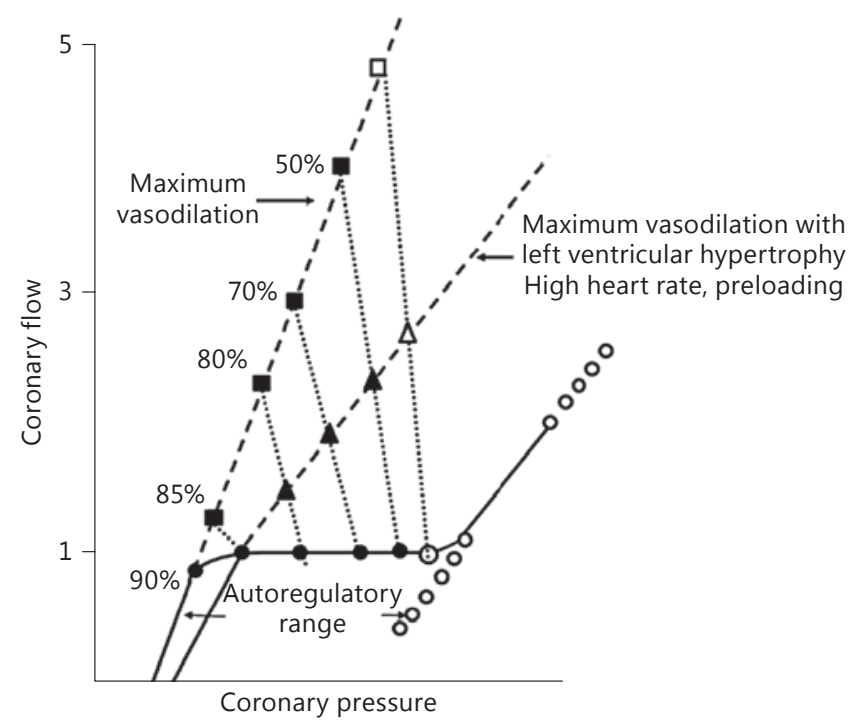

Fig. 1. Relationship between coronary flow (ratio of flow during vasodilation to flow before vasodilation) and pressure in the left ventricle at various degrees of stenosis (indicated by percentages) and with left ventricular hypertrophy, high heart rate, or preloading (reproduced with permission from Cruickshank [4]). Vasodilation without stenosis: open circles = under basal conditions; open squares = without hypertrophy, high heart rates, or preloading; open triangles = with hypertrophy, high heart rates, or preloading. Vasodilatation at various degrees of coronary stenosis: closed circles = under basal conditions; closed squares = without hypertrophy, high heart rates, or preloading; closed triangles = with hypertrophy, high heart rates, or preloading. Long dashed line = maximum vasodilatation; series of smaller circles = maximum vasoconstriction; short dashed line $=$ flow reserve.

Second, the J-curve phenomenon may also depend on the feature of regional circulation $[4,27,28]$. Coronary circulation is different from cerebral and renal circulation in blood flow regulation. In both cerebral and renal circulation, there is autoregulation mainly by adjusting the vessel diameter, but not resistance, because the peripheral resistance is generally low. For instance, the cerebral blood flow remains constant in arterial pressures ranging from approximately 60 to $160 \mathrm{~mm} \mathrm{Hg}$ [28]. However, coronary circulation has high peripheral resistance. When blood pressure is low, coronary circulation is more susceptible to the reduced perfusion pressure, especially in the presence of plaques and impaired flow reserve (fig. 1) [4]. Several blood pressure-lowering trials demonstrated divergent results on coronary and cerebral prevention $[19,29]$. In the Action to Control Cardiovascular Risk in Diabetes (ACCORD) trial, intensive blood pressure lowering to $120 \mathrm{~mm} \mathrm{Hg}$ systolic blood pressure, compared to 140 $\mathrm{mm} \mathrm{Hg}$, significantly reduced the risk of fatal and nonfatal stroke $(-41 \%)$ but did not influence the risk of coronary events (-6\%) [19]. Similar results were observed in the Nateglinide and Valsartan in Impaired Glucose Tolerance Outcomes Research (NAVIGATOR) trial ( $-21 \%$ and $-3 \%$, respectively) [29] (table 2).

Third, the J-curve phenomenon may be dependent on the joint effect of systolic and diastolic blood pressures. The highest systolic and the lowest diastolic blood pressures are measured within a cardiac cycle using the current techniques. However, blood pressure changes gradually and continuously from systole to diastole. It is, therefore, not appropriate to discuss the J-curve for systolic and diastolic blood pressures separately. In a recent study, 


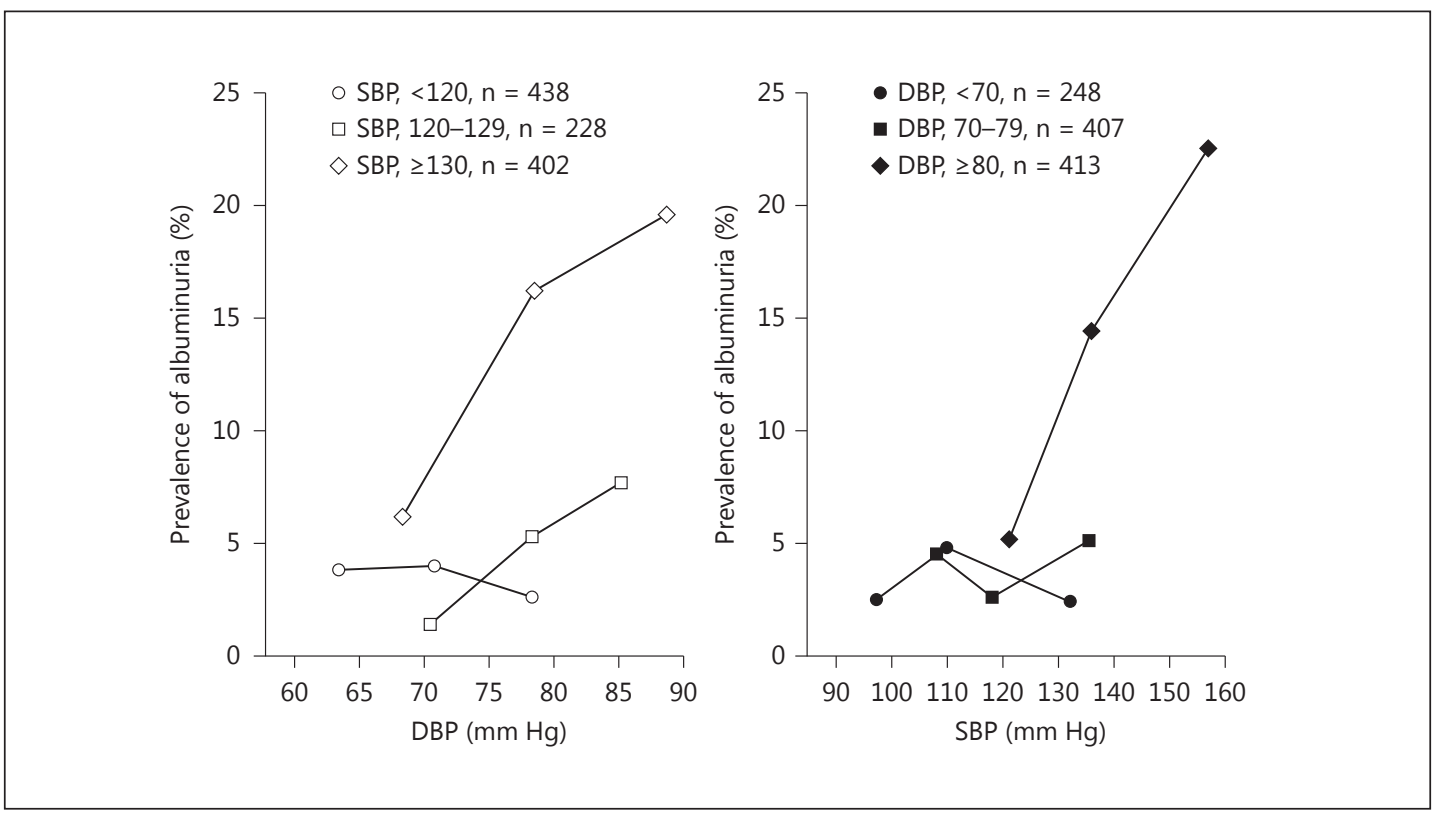

Fig. 2. Prevalence of albuminuria in relation to the joint effect of systolic (SBP) and diastolic blood pressures (DBP) (reproduced with permission from Sheng et al. [30]).

we investigated the single and joint effects of systolic and diastolic blood pressures on the risk of albuminuria [30]. A J-curve between the risk of albuminuria and blood pressure was observed for both systolic and diastolic blood pressure with nadir levels of 110 and $70 \mathrm{~mm}$ $\mathrm{Hg}$, respectively. However, there was no J-curve for systolic blood pressure whenever diastolic blood pressure was $80 \mathrm{~mm} \mathrm{Hg}$ or higher and for diastolic blood pressure whenever systolic blood pressure was $120 \mathrm{~mm} \mathrm{Hg}$ or higher. The risk of albuminuria was significantly ( $\mathrm{p} \leq 0.01)$ and positively associated with diastolic blood pressure in subjects with a systolic blood pressure of at least $130 \mathrm{~mm} \mathrm{Hg}$, and with systolic blood pressure in subjects with a diastolic blood pressure of at least $80 \mathrm{~mm} \mathrm{Hg}$ (fig. 2) [30].

Fourth, blood pressure variability may influence the J-curve phenomenon. For the diagnosis of hypertension and the evaluation of antihypertensive treatment, several blood pressure readings on several occasions are averaged. However, blood pressure changes over time. Increased blood pressure variability can be attributable to the high as well as the low pressure values. The extremely low pressure values may induce ischemia and ischemic events. This phenomenon may become prominent in patients with critical diseases, such as stroke. In our recently published Intensive Blood Pressure Reduction Trial 2 (INTERACT2), intensive blood pressure lowering had a modest beneficial effect on clinical outcomes in patients with acute primary intracerebral hemorrhage [31] (table 2). However, blood pressure variability was significantly associated with the risk of death and major disability (adjusted odds ratio 1.41, $\mathrm{p}=0.02$ for the top vs. the bottom fifth of the standard deviation of blood pressure during the first $24 \mathrm{~h}$ after randomization), independent of blood pressure level at baseline [32], indicating an effect of not only high extreme values but also of low extreme values. Too low blood pressure might be detrimental in these critically ill patients. 


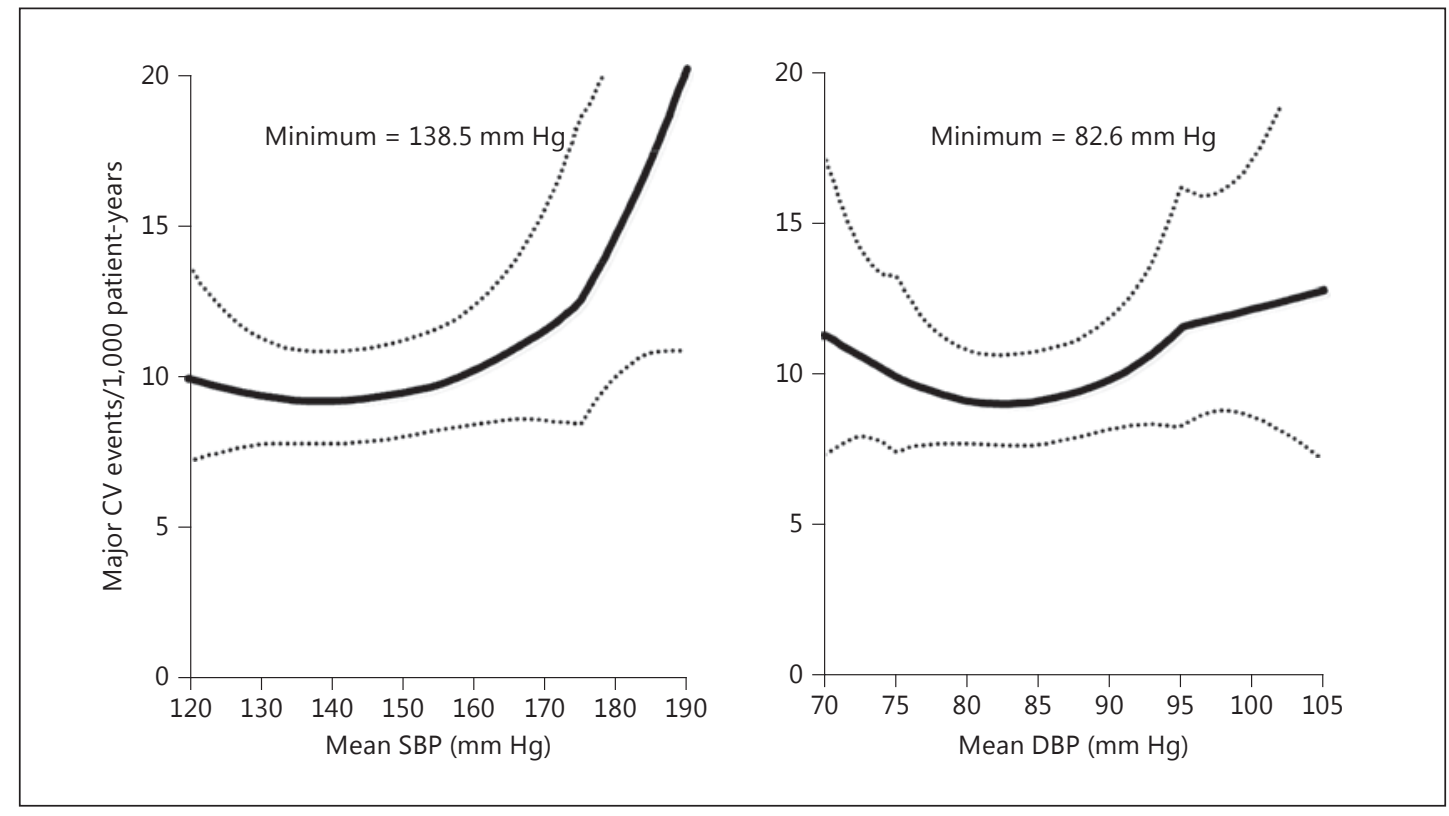

Fig. 3. Post hoc analysis of the nadir level of blood pressure in the HOT trial for major cardiovascular (CV) events (reproduced with permission from Hansson et al. [15]).

\section{The Evidence of the J-Curve Phenomenon}

\section{Evidence from Randomized Controlled Trials}

There is very little clinical trial evidence of the J-curve phenomenon. Nevertheless, the Hypertension Optimal Treatment (HOT) trial compared three levels of diastolic blood pressures, namely $<90,<85$, and $<80 \mathrm{~mm} \mathrm{Hg}$, respectively [15], and the ongoing Systolic Hypertension Optimal Treatment (SHOT) trial investigates three levels of systolic blood pressures, namely $<145,<135$, and $<125 \mathrm{~mm} \mathrm{Hg}$, respectively [16] (table 1).

The HOT trial was published in 1998 [15]. The difference in blood pressure reduction between the three groups was small and around 2.2/2.0 $\mathrm{mm} \mathrm{Hg}$ between the $<90$ and $<85$ $\mathrm{mm}$ Hg groups, and 1.9/2.0 $\mathrm{mm} \mathrm{Hg}$ between the $<85$ and $<80 \mathrm{~mm}$ Hg groups. For the comparisons between the three groups, statistical significance for clinical outcomes was achieved for myocardial infarction in the diabetic subgroup of patients but not in the overall study population or in the nondiabetic subgroup of patients or for other clinical outcomes, e.g. stroke [15]. The HOT investigators had to perform a post hoc analysis to investigate the nadir level of blood pressure based on the nonrandomized observational data. This post hoc analysis demonstrated that the nadir was $138.5 \mathrm{~mm} \mathrm{Hg}$ systolic blood pressure and $82.6 \mathrm{~mm} \mathrm{Hg}$ diastolic blood pressure (fig. 3) [15].

The SHOT trial is conducted in patients with a recent history of stroke [16]. The SHOT investigators plan to recruit 7,500 patients. The recruitment is ongoing in China and in European countries. It is hoped that the SHOT trial will provide evidence of whether or not there is a J-curve relationship between the level of systolic blood pressure and risk of stroke in the systolic blood pressure range from 125 to $145 \mathrm{~mm} \mathrm{Hg}$.

Several trials compared two levels of blood pressures according to a predefined target blood pressure [17-20] or two different treatments that led to a difference in blood pressure $[21,22]$ (table 2). These trials did not provide any trial evidence of the J-curve phenomenon, 
regardless of the results. At least three levels of blood pressure are required to show a J-curve relationship. Nonetheless, the contrasting results between ACCORD-BP [19] and the Systolic Blood Pressure Intervention Trial (SPRINT) [20] suggested a possible J-curve relationship even for stroke. The risk reduction in fatal and nonfatal stroke by intensive $(<120 \mathrm{~mm} \mathrm{Hg})$ compared to less intensive blood pressure lowering ( $<140 \mathrm{~mm} \mathrm{Hg}$ ) was only $11 \%$ in SPRINT [20], which was far less than that observed in ACCORD-BP (41\%) [19] and what would be expected from the $13.1 \mathrm{~mm} \mathrm{Hg}$ of systolic blood pressure reduction [5].

\section{Evidence from Observational Studies}

The J-curve phenomenon was first described in observational studies [3, 4]. Since then, numerous studies have investigated the relationship between blood pressure and clinical outcomes. The prospective studies collaboration included 61 prospective observational studies worldwide with 12,000 stroke deaths and 34,000 coronary deaths during 12.7 million person-years of follow-up. The investigators concluded that blood pressure was strongly and directly related to vascular mortality without any evidence of a threshold down to at least $115 / 75 \mathrm{~mm} \mathrm{Hg}$ [5]. However, if the figures depicting the relationship between blood pressure and stroke and coronary deaths were scrutinized, there would indeed be a J-curved relationship, especially for diastolic blood pressure. In the lowest diastolic pressure subgroup, the risk of stroke and coronary death tended to be similar as in the adjacent higher blood pressure subgroup and showed a shallow J-shaped relationship [5].

Several studies observed a strong J-curve phenomenon in an elderly population [33] or in patients with coronary heart disease [14], diabetes mellitus [34], or chronic kidney disease [35]. The results of these observational studies were often confounded by a reverse causality. For instance, several studies demonstrated that low blood pressure was associated with dementia $[23,36]$. This is probably because demented patients have malnutrition and, consequently, a low blood pressure. A similar mechanism may explain the J-curve relationship of blood pressure with heart failure mortality [37] and several other clinical conditions [38, 39]. Other factors, such as a selection bias or indication bias, may also compromise the validity of observational studies in the investigation of the J-curve issue.

\section{Observational Evidence from Antihypertensive Treatment Trials}

Although post hoc analyses of clinical trial data are observational in nature, there are several advantages over observational studies. First, the blood pressure level was mainly, though not entirely, achieved by antihypertensive treatment. Such a blood pressure can be considered as treatment induced and, therefore, is clinically relevant for the J-curve issue in antihypertensive therapy. Second, blood pressure was usually measured regularly and carefully. Blood pressure fluctuates substantially over time and across conditions. The more measurements obtained, the closer to the true pressure values and the more precise is blood pressure evaluation. Third, the collection of information on clinical outcomes is accurate and complete. Patients enrolled in a trial were followed up regularly. The occurrence of an event could be identified timely, and the data collection could then be done within a shorter time interval from occurrence. Fourth, antihypertensive treatment was usually homogeneous. This excludes, to some extent, the possibility that the difference in outcomes was actually the consequence of different treatments.

Early trials included patients with high blood pressure at entry and high goal pressure during treatment. Data from these trials, therefore, provide very little evidence of the J-curve issue in the blood pressure ranges from 120 to $140 \mathrm{~mm} \mathrm{Hg}$ systolic and from 80 to $90 \mathrm{~mm} \mathrm{Hg}$ diastolic. Recent studies included patients with mildly elevated blood pressure or even high normal blood pressure $[9,22,29,40]$ or defined a tight goal of blood pressure control $(<130 / 85 \mathrm{~mm} \mathrm{Hg}$ in the presence of diabetes mellitus or renal impairment) $[8,10,41]$ 
(table 1). The investigators from two clinical trials performed analyses of the relationship between achieved blood pressure and clinical outcomes [8-10].

The Telmisartan Alone and in Combination with Ramipril Global Endpoint Trial (ONTARGET) included 25,588 patients with coronary, peripheral, or cerebrovascular disease or diabetes mellitus [40]. Patients were treated with either telmisartan or ramipril alone or in combination from a mean systolic/diastolic blood pressure of 141.8/82.132 $\mathrm{mm} \mathrm{Hg}$ at baseline to approximately 132-135/76-78 mm Hg during follow-up [40]. In adjusted post hoc analyses, a J-shaped relationship was noticed in the lowest quartile of systolic blood pressure at entry $(<130 \mathrm{~mm} \mathrm{Hg}$ ) for total and cardiovascular mortality. Patients with a systolic blood pressure decrease had a significantly higher risk of total and cardiovascular mortality than those with a blood pressure increase of at least $10 \mathrm{~mm} \mathrm{Hg}$ from baseline. In a further analysis according to decile distributions of on-treatment systolic blood pressure, a J-curved relationship was seen for total and cardiovascular mortality and coronary events with a nadir level around $130 \mathrm{~mm} \mathrm{Hg}$, but not for fatal and nonfatal stroke [9].

The International Verapamil-Trandolapril Study (INVEST) compared two antihypertensive regimens based on verapamil or atenolol, respectively, in patients with coronary heart disease [41]. The goal of blood pressure control was $140 / 90$ or 130/85 mm Hg in the absence or presence of diabetes mellitus or renal impairment. In adjusted analyses in all subjects, a J-shaped relationship was observed for all clinical outcomes except stroke, particularly for diastolic blood pressure, with a nadir at 119/84 mm Hg [8]. In the subgroup of patients with diabetes mellitus, compared to patients whose systolic blood pressure during follow-up was $140 \mathrm{~mm} \mathrm{Hg}$ or higher, patients who achieved a lower systolic blood pressure ( $<140 \mathrm{~mm} \mathrm{Hg}$ ) had significantly improved clinical outcomes. However, further lowering of systolic blood pressure to a level below $130 \mathrm{~mm} \mathrm{Hg}$ did not provide an additional health benefit [10].

Similar analyses were performed for many other antihypertensive treatment trials [42, 43]. The results of these analyses were similar, indicating a nadir level of approximately 130 $\mathrm{mm} \mathrm{Hg}$ systolic blood pressure and $80 \mathrm{~mm} \mathrm{Hg}$ diastolic blood pressure. Further reducing blood pressure to an even lower level either had no further benefit or increased the risks of clinical outcomes.

\section{Conclusions and Future Perspectives}

Although there is very little clinical trial evidence of the J-curve issue, there is abundant observational evidence indicating a nadir level of blood pressure below which blood pressure lowering might be detrimental. The currently ongoing SHOT trial might provide more evidence of this issue for fatal and nonfatal stroke and probably also for other clinical outcomes [16]. However, the optimal blood pressure might be different between individuals and across outcomes. Indeed, $120 \mathrm{~mm} \mathrm{Hg}$ of systolic blood pressure compared to $140 \mathrm{~mm} \mathrm{Hg} \mathrm{might}$ prevent stroke in diabetic patients [19] and heart failure in nondiabetic patients [20]. However, it is probably too naive to attempt to find a universal optimal blood pressure level for all patients. Nonetheless, it is probably possible to find a universal beneficial blood pressure level for most hypertensive patients. If we would continue defining hypertension as a blood pressure of at least $140 \mathrm{~mm} \mathrm{Hg}$ systolic and $90 \mathrm{~mm} \mathrm{Hg}$ diastolic, 130/80 mm Hg might be beneficial to most patients. As recommended by some [44], though not all [45], current hypertension guidelines, it would be appropriate to control clinic blood pressure to a level below 140/90 mm Hg in general and below 130/80 mm Hg in various groups of patients at high cardiovascular risk, such as those with diabetes mellitus or chronic kidney disease. To consolidate the latter recommendation, future randomized controlled trials may compare 
$130 \mathrm{~mm} \mathrm{Hg}$ to $140 \mathrm{~mm} \mathrm{Hg}$ of systolic blood pressure as a therapeutic target for cardiovascular prevention, with the simultaneous use of modern blood pressure measuring techniques, such as ambulatory and home blood pressure monitoring.

\section{Disclosure Statement}

Y.-Y.K. declares no conflict of interest. J.-G.W. reports receiving lecture and consulting fees from DaiichiSankyo, MSD, Novartis, Omron, Pfizer, Sanofi, and Servier.

\section{References}

1 Veterans Administration Cooperative Study Group on Antihypertensive Agents: Effects of treatment on morbidity in hypertension. Results in patients with diastolic blood pressures averaging 115 through $129 \mathrm{~mm}$ Hg. JAMA 1967;202:1028-1034.

2 Veterans Administration Cooperative Study Group on Antihypertensive Agents: Effects of treatment on morbidity in hypertension. II. Results in patients with diastolic blood pressure averaging 90 through $114 \mathrm{~mm}$ Hg. JAMA 1970;213:1143-1152.

3 Stewart IMG: Relation of reduction in pressure to first myocardial infarction in patients receiving treatment for severe hypertension. Lancet 1979;313:861-865.

4 Cruickshank JM: Coronary flow reserve and the J curve relation between diastolic blood pressure and myocardial infarction. BMJ 1988;297:1227-1230.

5 Prospective Studies Collaboration: Age-specific relevance of usual blood pressure to vascular mortality: a meta-analysis of individual data for one million adults in 61 prospective studies. Lancet 2002;360:1903-1913.

6 D’Agostino RB, Belanger AJ, Kannel WB, Cruickshank JM: Relation of low diastolic blood pressure to coronary heart disease death in presence of myocardial infarction: the Framingham Study. BMJ 1991;303:385-389.

7 Boutitie F, Gueyffier F, Pocock S, Fagard R, Boissel JP: J-shaped relationship between blood pressure and mortality in hypertensive patients: new insights from a meta-analysis of individual-patient data. Ann Intern Med 2002;136:438-448.

8 Messerli FH, Mancia G, Conti CR, Hewkin AC, Kupfer S, Champion A, Kolloch R, Benetos A, Pepine CJ: Dogma disputed: can aggressively lowering blood pressure in hypertensive patients with coronary artery disease be dangerous? Ann Intern Med 2006;144:884-893.

9 Sleight P, Redon J, Verdecchia P, Mancia G, Gao P, Fagard R, Schumacher H, Weber M, Bohm M, Williams B, Pogue J, Koon T, Yusuf S: Prognostic value of blood pressure in patients with high vascular risk in the Ongoing Telmisartan Alone and in Combination with Ramipril Global Endpoint Trial study. J Hypertens 2009;27:1360-1369.

10 Cooper-DeHoff RM, Gong Y, Handberg EM, Bavry AA, Denardo SJ, Bakris GL, Pepine CJ: Tight blood pressure control and cardiovascular outcomes among hypertensive patients with diabetes and coronary artery disease. JAMA 2010;304:61-68.

11 Bangalore S, Qin J, Sloan S, Murphy SA, Cannon CP: What is the optimal blood pressure in patients after acute coronary syndromes? Relationship of blood pressure and cardiovascular events in the Pravastatin or Atorvastatin Evaluation and Infection Therapy-Thrombolysis in Myocardial Infarction (PROVE IT-TIMI) 22 Trial. Circulation 2010;122:2142-2151.

12 Bangalore S, Messerli FH, Wun CC, Zuckerman AL, DeMicco D, Kostis JB, LaRosa JC: J-curve revisited: an analysis of blood pressure and cardiovascular events in the Treating to New Targets (TNT) Trial. Eur Heart J 2010;31:2897-2908.

13 Anderson RJ, Bahn GD, Moritz TE, Kaufman D, Abraira C, Duckworth W: Blood pressure and cardiovascular disease risk in the Veterans Affairs Diabetes Trial. Diabetes Care 2011;34:34-38.

14 Dorresteijn JA, van der Graaf Y, Spiering W, Grobbee DE, Bots ML, Visseren FL; Secondary Manifestations of Arterial Disease Study Group: Relation between blood pressure and vascular events and mortality in patients with manifest vascular disease: J-curve revisited. Hypertension 2012;59:14-21.

15 Hansson L, Zanchetti A, Carruthers SG, Dahlof B, Elmfeldt D, Julius S, Ménard J, Rahn KH, Wedel H, Westerling S: Effects of intensive blood-pressure lowering and low-dose aspirin in patients with hypertension: principal results of the Hypertension Optimal Treatment (HOT) randomised trial. Lancet 1998;351:1755-1762.

16 Zanchetti A, Liu L, Mancia G, Parati G, Grassi G, Stramba-Badiale M, Silani V, Bilo G, Corrao G, Zambon A, Scotti L, Zhang X, Wang H, Zhang Y, Zhang X, Guan TR, Berge E, Redon J, Narkiewicz K, Dominiczak A, Nilsson P, Viigimaa M, LaurentS, Agabiti-Rosei E, Wu Z, Zhu D, Rodicio JL, Ruilope LM, Martell-Claros N, Pinto F, Schmieder RE, Burnier M, Banach M, Cifkova R, Farsang C, Konradi A, Lazareva I, Sirenko Y, Dorobantu M, Postadzhiyan A, Accetto R, Jelakovic B, Lovic D, Manolis AJ, Stylianou P, Erdine S, Dicker D, Wei G, Xu C, Xie H, Coca A, O'Brien J, Ford G: Blood pressure and LDL-cholesterol targets for prevention of recurrent strokes and cognitive decline in the hypertensive patient: design of the European Society of Hypertension-Chinese Hypertension League Stroke in Hypertension Optimal Treatment randomized trial. J Hypertens 2014;32:1888-1897. 
Kang and Wang: The J-Curve Phenomenon in Hypertension

17 The JATOS Study Group: Principal results of the Japanese Trial to Assess Optimal Systolic Blood Pressure in Elderly Hypertensive Patients (JATOS). Hypertens Res 2008;31:2115-2127.

18 Ogihara T, Saruta T, Rakugi H, Matsuoka H, Shimamoto K, Shimada K, Imai Y, Kikuchi K, Ito S, Eto T, Kimura G, Imaizumi T, Takishita S, Ueshima H; Valsartan in Elderly Isolated Systolic Hypertension Study Group: Target blood pressure for treatment of isolated systolic hypertension in the elderly: valsartan in elderly isolated systolic hypertension study. Hypertension 2010;56:196-202.

19 The ACCORD Study Group: Effects of intensive blood-pressure control in type 2 diabetes mellitus. N Engl J Med 2010;362:1575-1585.

20 The SPRINT Research Group: A randomized trial of intensive versus standard blood-pressure control. N Engl J Med 2015;373:2103-2116.

21 The ADVANCE Collaborative Group: Effects of a fixed combination of perindopril and indapamide on macrovascular and microvascular outcomes in patients with type 2 diabetes mellitus (the ADVANCE trial): a randomized controlled trial. Lancet 2007;370:829-840.

22 Haller H, Ito S, Izzo JL Jr, Januszewicz A, Katayama S, Menne J, Mimran A, Rabelink TJ, Ritz E, Ruilope LM, Rump LC, Viberti G; ROADMAP Trial Investigators: Olmesartan for the delay or prevention of microalbuminuria in type 2 diabetes. N Engl J Med 2011;364:907-917.

23 Guo Z, Viitanen M, Fratiglioni L, Winblad B: Low blood pressure and dementia in elderly people: the Kungsholmen project. BMJ 1996;312:805-808.

24 Irie K, Yamaguchi T, Minematsu K, Omae T: The J-curve phenomenon in stroke recurrence. Stroke 1993;24: 1844-1849.

25 Rothwell PM, Howard SC, Spence JD; Carotid Endarterectomy Trialists' Collaboration: Relationship between blood pressure and stroke risk in patients with symptomatic carotid occlusive disease. Stroke 2003;34:25832590.

26 Kenchaiah S, Pfeffer MA: Cardiac remodeling in systemic hypertension. Med Clin North Am 2004;88:115-130.

27 O'Rourke MF, Safar ME: Relationship between aortic stiffening and microvascular disease in brain and kidney: cause and logic of therapy. Hypertension 2005;46:200-204.

28 Tzeng YC, Ainslie PN: Blood pressure regulation IX: cerebral autoregulation under blood pressure challenges. Eur J Appl Physiol 2014;114:545-559.

29 The NAVIGATOR Study Group: Effect of valsartan on the incidence of diabetes and cardiovascular events. N Engl J Med 2010;362:1477-1490.

30 Sheng CS, Liu M, Zou J, Huang QF, Li Y, Wang JG: Albuminuria in relation to the single and combined effects of systolic and diastolic blood pressure in Chinese. Blood Press 2013;22:158-164.

31 Anderson CS, Heeley E, Huang Y, Wang J, Stapf C, Delcourt C, Lindley R, Robinson T, Lavados P, Neal B, Hata J, Arima H, Parsons M, Li Y, Wang J, Heritier S, Li Q, Woodward M, Simes RJ, Davis SM, Chalmers J; the INTERACT2 Investigators: Rapid blood-pressure lowering in patients with acute intracerebral hemorrhage. N Engl J Med 2013;368:2355-2365.

32 Manning L, Hirakawa Y, Arima H, Wang X, Chalmers J, Wang J, Lindley R, Heeley E, Delcourt C, Neal B, Lavados P, Davis SM, Tzourio C, Huang Y, Stapf C, Woodward M, Rothwell PM, Robinson TG, Anderson CS; INTERACT2 Investigators: Blood pressure variability and outcome after acute intracerebral haemorrhage: a post-hoc analysis of INTERACT2, a randomised controlled trial. Lancet Neurol 2014;13:364-373.

33 Tervahauta M, Pekkanen J, Enlund H, Nissinen A: Change in blood pressure and 5-year risk of coronary heart disease among elderly men: the Finnish cohorts of the Seven Countries Study. J Hypertens 1994;12:11831189.

34 Sundström J, Sheikhi R, Ostgren CJ, Svennblad B, Bodegård J, Nilsson PM, Johansson G: Blood pressure levels and risk of cardiovascular events and mortality in type-2 diabetes: cohort study of 34,009 primary care patients. J Hypertens 2013;31:1603-1610.

35 Kovesdy CP, Lu JL, Molnar MZ, Ma JZ, Canada RB, Streja E, Kalantar-Zadeh K, Bleyer AJ: Observational modeling of strict versus conventional blood pressure control in patients with chronic kidney disease. JAMA Intern Med 2014;174:1442-1449.

36 Razay G, Williams J, King E, Smith AD, Wilcock G: Blood pressure, dementia and Alzheimer's disease: the OPTIMA longitudinal study. Dement Geriatr Cogn Disord 2009;28:70-74.

37 Lee DS, Ghosh N, Floras JS, Newton GE, Austin PC, Wang X, Liu PP, Stukel TA, Tu JV: Association of blood pressure at hospital discharge with mortality in patients diagnosed with heart failure. Circ Heart Fail 2009;2: 616-623.

38 Witteman JC, Grobbee DE, Valkenburg HA, van Hemert AM, Stijnen T, Burger H, Hofman A: J-shaped relation between change in diastolic blood pressure and progression of aortic atherosclerosis. Lancet 1994;343:504507.

39 Flack JM, Neaton J, Grimm R Jr, Shih J, Cutler J, Ensrud K, MacMahon S: Blood pressure and mortality among men with prior myocardial infarction: Multiple Risk Factor Intervention Trial Research Group. Circulation 1995;92:2437-2445.

40 The ONTARGET Investigators: Telmisartan, ramipril, or both in patients at high risk for vascular events. N Engl J Med 2008;358:1547-1559. 
41 Pepine CJ, Handberg EM, Cooper-DeHoff RM, Marks RG, Kowey P, Messerli FH, Mancia G, Cangiano JL, GarciaBarreto D, Keltai M, Erdine S, Bristol HA, Kolb HR, Bakris GL, Cohen JD, Parmley WW: A calcium antagonist versus a non-calcium antagonist hypertension treatment strategy for patients with coronary artery disease. The International Verapamil-Trandolapril Study (INVEST): a randomized controlled trial. JAMA 2003;290: 2805-2816.

42 Mancia G, Kjeldsen SE, Zappe DH, Holzhauer B, Hua TA, Zanchetti A, Julius S, Weber MA: Cardiovascular outcomes at different on-treatment blood pressures in the hypertensive patients of the VALUE trial. Eur Heart J 2015, Epub ahead of print.

43 Okin PM, Hille DA, Kjeldsen SE, Dahlöf B, Devereux RB: Impact of lower achieved blood pressure on outcomes in hypertensive patients. J Hypertens 2012;30:802-810.

44 Shimamoto K, Ando K, Fujita T, Hasebe N, Higaki J, Horiuchi M, Imai Y, Imaizumi T, Ishimitsu T, Ito M, Ito S, Itoh H, Iwao H, Kai H, Kario K, Kashihara N, Kawano Y, Kim-Mitsuyama S, Kimura G, Kohara K, Komuro I, Kumagai H, Matsuura H, Miura K, Morishita R, Naruse M, Node K, Ohya Y, Rakugi H, Saito I, Saitoh S, Shimada K, Shimosawa T, Suzuki H, Tamura K, Tanahashi N, Tsuchihashi T, Uchiyama M, Ueda S, Umemura S; Japanese Society of Hypertension Committee for Guidelines for the Management of Hypertension: The Japanese Society of Hypertension Guidelines for the Management of Hypertension (JSH 2014). Hypertens Res 2014;37:253390.

45 James PA, Oparil S, Carter BL, Cushman WC, Dennison-Himmelfarb C, Handler J, Lackland DT, LeFevre ML, MacKenzie TD, Ogedegbe O, Smith SC Jr, Svetkey LP, Taler SJ, Townsend RR, Wright JT Jr, Narva AS, Ortiz E: 2014 evidence-based guideline for the management of high blood pressure in adults: report from the panel members appointed to the Eighth Joint National Committee (JNC 8). JAMA 2014;311:507-520. 